\title{
Educating physicians prepared to improve care and safety is no accident: it requires a systematic approach
}

\author{
D C Aron, L A Headrick
}

Qual Saf Health Care 2002;11:168-173

While most newly qualified physicians are well prepared in the science base of medicine and in the skills that enable them to look after individual patients, few have the skills necessary to improve care and patient safety continuously. We apply a systems analysis from the field of human error to identify ways in which medical school education can increase the number of graduates prepared to reflect on and improve professional practice. Doing so requires a systematic approach involving entrance requirements, the curriculum, the organizational culture of training environments, student assessment, and program evaluation.

See end of article for authors' affiliations

Correspondence to: Dr D C Aron, Education Office 14(W), Louis Stokes Cleveland DVA Medical Center, 10701 East Blvd, Cleveland, $\mathrm{OH} 44106$,

USA; david.aron@

med.va.gov

Accepted for publication 24 April 2002
$\mathrm{D}$ ctors who graduate from most medical schools throughout the world are well prepared in the science base of medicine and in skills that enable them to look after individual patients. However, few newly qualified physicians have the skills necessary to improve care and patient safety. These include the ability to perceive and work effectively in interdependencies; the collecting, aggregating, analyzing, and displaying data on processes and outcomes of care; skills in designing healthcare processes; the ability to work in teams and in collaboration with managers and patients; and the willingness to examine honestly and learn from mistakes. ${ }^{12}$ We apply a systems approach from the field of human error to medical school education which shows that the graduation of physicians prepared to improve care is no accident; it requires attention to the educational system as a whole.

\section{MODEL OF SYSTEM FAILURE}

A system model that helps to explain error maintains that errors are consequences rather than causes-that is, as Reason ${ }^{2}$ argues, they are derived from systemic factors rather than human failings. Humans are fallible and errors are to be expected even in the best organizations. ${ }^{2}{ }^{3}$ Errors arise in "upstream" systemic factors such as policies and procedures that make error easier and safe practice more difficult. For example, intravenous infusions account for a significant portion of the adverse drug events in hospitals. ${ }^{4}$ When non-standard concentrations of intravenous solutions are used, mixing errors are more likely. When the floor stock of intravenous infusions is extensive, "look alike" errors increase. Humans ability to understand work as a process; skill in may make the active errors that precipitate the adverse event-administration of the incorrect concentration or the wrong drug altogether-but these are symptoms of the latent errors that exist in the system. This conceptual approach concentrates on the conditions under which humans work. It seeks out and removes the error provoking properties within the system at large. This is accomplished by addressing weaknesses in the system defences against error (fig 1).

Central to the system model of error reduction is the concept of system defences. All hazardous technologies, including medical care, possess layers of barriers and safeguards. These defences take a variety of forms: technological, administrative, educational. Most important is culture-the cluster of attitudes, beliefs and values held by the individuals of the organization. Ideally, in combination the defensive layers are impermeable. In reality there are always weaknesses in the defences. The layers are more like slices of Swiss cheese containing many holes that are continually opening, shutting, and altering their positions. Fortunately, because there are multiple layers, the presence of holes in any one "slice" normally does not cause a bad outcome. If there is a hole in one, another defence will prevent the hazard from causing damage. For a mishap to occur, the holes in many layers have to line up, at least momentarily, to permit a trajectory of accident opportunity-bringing hazards. When an adverse event occurs, the important issue is not who blundered, but how and why the defences failed. We believe that a similar model can be applied to the training of a physician (fig 1).

This approach contrasts with the traditional person oriented approach dominant in health care where the focus for errors and unsafe acts is on personal responsibility of those at the site of care delivery. Personal failures such as carelessness are considered aberrant mental processes at best, and moral failings at worst. In a just world only bad people do bad things. Efforts to reduce error thus emphasize blame, disciplinary measures, retraining, and new policies, but ignore the context in which the error occurred. Reason contends that this approach has serious shortcomings, is ill suited to the medical domain, and may be counterproductive.

Medical schools have mechanisms-or "organizational defences"-to prevent the qualification/graduation of physicians who lack the necessary competencies to practice medicine. These organizational defences include entrance requirements, the curriculum, the organizational culture of training environments, student assessment, and program evaluation (table 1). We must identify and address the holes in these defences 


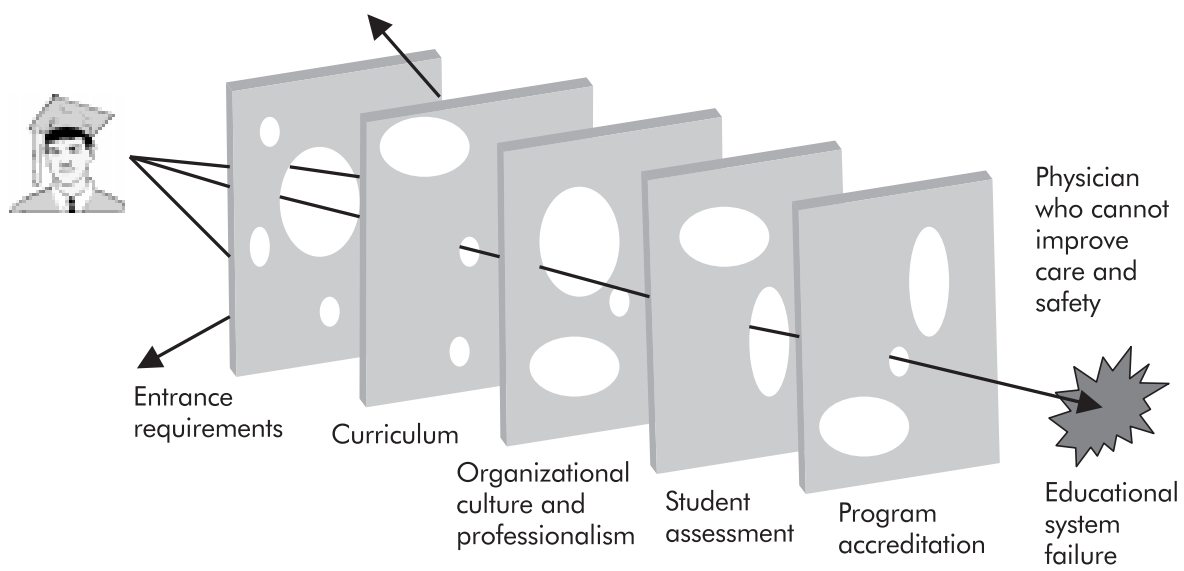

Figure 1 Defences against the graduation of physicians unable to improve their practice continuously (after Reason ${ }^{2}$ ).

that might result in the graduation of physicians who are unable to improve care and patient safety.

\section{ORGANIZATIONAL DEFENCES}

\section{Entrance requirements}

Choosing individuals who can become the best physicians is a critical step. ${ }^{5}$ Does the current process address the core abilities needed for improvement? Admission to medical school is very competitive and differentiation between individuals is difficult. A process based on grades and test scores is the primary method used because of its purported ability to predict performance in medical school. In fact, grades and scores are particularly good at predicting classroom performance (which is tested in the same way), and much less good at predicting clinical performance (which tends to be assessed differently). ${ }^{78}$ Moreover, while such examinations may be useful in demonstrating some aspects of competence, they are not useful in assessing the extent to which individuals can adapt to change, generate new knowledge, and continue to improve their performance. ${ }^{9}$

The quantitative approach to candidate selection is convenient as it allows one to rank applicants and schools (box 1) using standardized numbers. This is supplemented by qualitative data collected from student essays, letters of recommendation, and interviews meant to inform the admissions committees about the integrity, values, commitment,

\section{Box 1 Medical school ranking by league table}

The magazine US News and World Report ranks US medical schools in league tables widely read by students, faculty, and medical school deans. ${ }^{43}$ The magazine uses two methods to rank schools, both of which rely heavily on the college grade point average (GPA) and Medical College Admission Test (MCAT) scores of the students they enrol. MCAT score and mean undergraduate GPA count for $65 \%$ and $30 \%$, respectively, of the student selectivity criteria which, in turn count for $20 \%$ of the score to rank schools in research and $15 \%$ in primary care.

communication skills, and interpersonal skills of the applicants. Such qualitative data have their own limitations and quantitative data easily become dominant. This may have pernicious effects such as competitiveness and grade consciousness among students applying to medical school. For example, a study of students at Harvard Medical School ${ }^{10}$ found that the so called "premedical" syndrome-in which premedical students become study machines and are characterized as hypercompetitive, narrow minded, greedy, and dishonest at best and "ferocious geeks" at worst-was in evidence.

Although considerable effort is made to ensure that medical students have the potential to become good physicians, up to

Table 1 Organizational defences, holes, and proposed means to strengthen the defences

\begin{tabular}{|c|c|c|}
\hline Organizational defences & Holes & Proposed means to strengthen the defences \\
\hline Entrance requirements & $\begin{array}{l}\text { - Score based selection criteria may not identify individuals with } \\
\text { ability to reflect on practice, work with others and continually } \\
\text { improve their performance }\end{array}$ & $\begin{array}{l}\text { - Include an assessment of prior experience and skills } \\
\text { in these areas as part of student selection }\end{array}$ \\
\hline Curriculum & $\begin{array}{l}\text { - Lack of attention to the skills needed to improve one's practice, } \\
\text { including collaboration, interdisciplinary teamwork and the ability } \\
\text { to admit and discuss error }\end{array}$ & $\begin{array}{l}\text { - Modify content to include core content in } \\
\text { improvement, including team training } \\
\text { - Emphasize value of learning from error }\end{array}$ \\
\hline Organizational culture & $\begin{array}{l}\text { - Overemphasis on physician/physician interaction, chronic } \\
\text { fatigue and other threats to professionalism } \\
\text { - Insufficient value placed on scholarship of teaching and } \\
\text { improvement } \\
\text { - Person oriented model of error }\end{array}$ & $\begin{array}{l}\text { - Address threats to professionalism } \\
\text { - Align organizational values with desired goals } \\
\text { - Seek training opportunities in organizations with } \\
\text { cultures that support safety and improvement }\end{array}$ \\
\hline Student assessment & $\begin{array}{l}\text { - Mismatch between what we measure and our real objectives } \\
\text { - Lack of assessment related to improvement and patient safety }\end{array}$ & $\begin{array}{l}\text { Develop approaches to student assessment that } \\
\text { address all required competencies }\end{array}$ \\
\hline Program evaluation & $\begin{array}{l}\text { - Accreditation standards do not address sufficiently the skills } \\
\text { needed by physicians to improve care and safety }\end{array}$ & $\begin{array}{l}\text { - Develop broader approaches to program evaluation } \\
\text { - Increase accountability for outcomes }\end{array}$ \\
\hline
\end{tabular}


now this has not explicitly included the attitudes and behaviors needed for improving care and safety. If students lack the integrity and willingness to engage in honest self-reflection, a school of medicine must try to instill those values. If students lack the ability to work with others, it is left to the medical school to help them to learn how. These are daunting tasks. A better organizational defence might be to include an assessment of prior experience and skills in these areas as part of the process of student selection.

\section{Curriculum}

The content of a typical medical school curriculum includes the sciences basic to medicine, a variety of clinical disciplines, and ethical, behavioral, and social subjects pertinent to medicine. This extensive curriculum equips qualified doctors to care for individual patients, one at a time. Less attention is paid to the skills necessary to improve one's practice as a whole. ${ }^{11}$ Table 2 summarizes the core domains of knowledge needed for competency in the improvement of health care.

Improvement in healthcare delivery (even one's own practice) is almost always an interdisciplinary process, requiring the expertise and collaboration of everyone who works in the system to be redesigned. The professionals involved must be ready to contribute their own knowledge and skills and be willing to learn from the expertise of others. Each must also be aware of differences such as language and methods of work that, unrecognized, can interfere with effective collaboration.

High reliability industries such as aviation and nuclear power recognize this need and their training emphasizes teamwork. ${ }^{12}{ }^{13}$ For example, in aviation "crew resource management" (CRM), originally termed "cockpit resource management", emphasizes such training. A study by Sexton et $a l,{ }^{14}$ which compared the views about teamwork of flight crews and hospital operating room personnel, is telling. In this study, which involved surveys performed over several years in several countries, aircrew and operating room personnel differed substantially in their view of how teams should work. While there was overwhelming support for flat hierarchies by airline crew members (94\%), only 55\% of attending surgeons preferred flat hierarchies. Moreover, different operating room personnel perceived the level of teamwork very differently. Surgical residents and attending physicians reported high levels of teamwork ( $73 \%$ and $64 \%$, respectively), but only $39 \%$ of attending anesthesiologists, $28 \%$ of surgical nurses, $25 \%$ of anesthesia nurses, and $10 \%$ of anesthesia residents reported high levels of teamwork. High reliability industries also recognize that human flexibility to adapt to changing events is an important safeguard against catastrophic accidents. Their training emphasizes the rehearsal (simulation) of both familiar and novel scenarios of failure. It is through this type of training that the ability to perceive and work effectively in interdependencies can be fostered.

Examples of team training and simulation in health care are relatively sparse. Training in advanced cardiac life support includes some of these elements and is one of the few instances involving large numbers of individuals. There are some examples of applying the CRM approach, primarily in the training of anesthesiologists and in the intensive care unit, emergency room, and labor and delivery room settings. ${ }^{15-18}$

Table 2 Core domains of knowledge for the improvement of health care

\begin{tabular}{|c|c|c|}
\hline Content area & Definition & Example learning objectives \\
\hline Customer/beneficiary knowledge & $\begin{array}{l}\text { Identification of the person, persons, or groups of persons for } \\
\text { whom health care is provided; an understanding of their needs } \\
\text { and preferences and the relationship of health care to those } \\
\text { needs and preferences }\end{array}$ & $\begin{array}{l}\text { For a particular health care service: } \\
\text { - Identify those whom we seek to serve } \\
\text { - Describe methods to identify their needs }\end{array}$ \\
\hline Health care as process, system & $\begin{array}{l}\text { The interdependent people (patients, families, eligible } \\
\text { populations, caregivers), procedures, activities, and } \\
\text { technologies of health care giving that come together to meet } \\
\text { the need(s) of individuals and communities }\end{array}$ & $\begin{array}{l}\text { - Describe care as a process } \\
\text { - Analyze data on processes of care }\end{array}$ \\
\hline Variation and measurement & $\begin{array}{l}\text { The use of measurement to understand the variation across and } \\
\text { within systems to improve the design and redesign of health } \\
\text { care }\end{array}$ & $\begin{array}{l}\text { - Collect and analyze data on outcomes of care } \\
\text { - Use data to identify changes that might decrease } \\
\text { unwanted variation in the outcomes of care }\end{array}$ \\
\hline $\begin{array}{l}\text { Leading, following and making } \\
\text { changes in health care }\end{array}$ & $\begin{array}{l}\text { The methods and skills for making change in complex } \\
\text { organizations, including the general and strategic management } \\
\text { of people and the healthcare work they do. Such activities } \\
\text { include a general understanding of healthcare financing, } \\
\text { information technology, the roles that individuals of different } \\
\text { professions play in daily health care giving, and the } \\
\text { development of a supportive internal organizational climate for } \\
\text { working, learning and caring }\end{array}$ & Describe core concepts for managing change \\
\hline Collaboration & $\begin{array}{l}\text { The knowledge, methods, and skills needed to work effectively } \\
\text { in groups, to understand and value the perspectives and } \\
\text { responsibilities of others, and the capacity to foster the same in } \\
\text { others }\end{array}$ & $\begin{array}{l}\text { - Work effectively in interdisciplinary teams } \\
\text { - Describe why an interdisciplinary approach is } \\
\text { necessary for improvement in health care }\end{array}$ \\
\hline $\begin{array}{l}\text { Developing new locally useful } \\
\text { knowledge }\end{array}$ & $\begin{array}{l}\text { The recognition of the need for new knowledge in personal } \\
\text { daily health professional practice and the skill to develop new } \\
\text { knowledge through empiric testing }\end{array}$ & $\begin{array}{l}\text { - Conduct serial experiments of improvement (also } \\
\text { known as Plan-Do-Study-Act cycles) } \\
\text { - Apply continuous improvement to personal learning } \\
\text { and change }\end{array}$ \\
\hline Social context and accountability & $\begin{array}{l}\text { An understanding of the social contexts (local, regional, } \\
\text { national, global) of health care and the way that expectations } \\
\text { arising from them are made explicit. This specifically includes } \\
\text { an understanding of the financial impact and costs of health } \\
\text { care }\end{array}$ & $\begin{array}{l}\text { - Describe the linkage of quality and cost in health } \\
\text { care } \\
\text { - Apply continuous improvement within the current } \\
\text { context of health care delivery }\end{array}$ \\
\hline Professional subject matter & $\begin{array}{l}\text { The health professional knowledge appropriate for a specific } \\
\text { discipline and the ability to apply and connect it to all of the } \\
\text { above }\end{array}$ & $\begin{array}{l}\text { - Identify and evaluate the literature defining best } \\
\text { practice }\end{array}$ \\
\hline
\end{tabular}

Modified from Batalden et al. ${ }^{11}$ 
Notwithstanding the limited number of studies in health care, the successful implementation of CRM in aviation suggests that this method has something to offer the training of physicians.

Systematic implementation of interdisciplinary training of any kind has not taken place in medical education, ${ }^{19}{ }^{20}$ despite many examples of interdisciplinary efforts that successfully improved care. ${ }^{21} 22$ If interdisciplinary training is to be implemented, we suggest that it should begin early, before learners become "isolated in their discipline specific domains and 'tainted' by traditional disciplinary hierarchies, boundaries and biases". ${ }^{23}$

Medical school curricula lack another important topic that constitutes a critical part of the way that high reliability organizations prevent error. In high reliability industries, near misses that result from error are considered an opportunity to improve the system as a whole. ${ }^{13}$ Although most physicians would state that they learn from their mistakes, teaching about the value of error is not included in most medical curricula. ${ }^{24}$ Moving away from an approach of "name, blame and shame" towards a "no blame" scenario where errors can be more openly admitted and discussed can help to develop an atmosphere where we all can learn from error. In addition, it can foster a sense of responsibility for error and responsibility for reporting it. However, it is important to recognize the emotional costs of involvement with a medical error and the need for appropriate emotional support. Where do medical students learn to perceive error as a character flaw? Apart from what individuals bring with them when they enter medical school, they are socialized to the profession and to the cultures of the organizations in which they train.

\section{Organizational culture}

Organizational culture strongly influences practice, ${ }^{25}$ including the ability to improve care and patient safety. We consider only two of the cultures in which medical students are socialized-the culture of the medical profession and the culture of the medical school and academic medical center. Socialization refers to the processes by which individuals come to understand and internalize the attitudes and values inherent in a particular social role and which are distinct from those of society in general. ${ }^{26}$ This helps to explain the behavior of individuals in work settings.

The high financial, social, economic, and psychological investment involved in the arduous training of a medical student promotes strong bonds with those who have the same interests and experiences. Sinclair found that physician/ physician cooperation was paramount throughout the years of training. ${ }^{27}$ Tribalism is encouraged by the apprenticeship style of medical education in which students learn to be doctors as part of tightly knit physician teams, especially in the hospital. This important learnt disposition may help to explain the reluctance of physicians to criticize other physicians and why, when challenged, they turn to each other rather than seek help outside the medical network. ${ }^{24}{ }^{27}$ Doctors may also turn to each other when faced with a medical error because of the learnt disposition of the value of experience (gained by seeing patients) and responsibility (gained by having patients and treating them). Feelings of elitism, collegiality, and exclusivity of professional judgement foster a belief in the necessity of self-regulation: no one else can understand. The result may be professional leniency, contributing to future medical errors.

Professionalism in medicine, defined by the American Board of Internal Medicine (ABIM), requires the physician to serve the interests of the patient above his or her selfinterest. ${ }^{28-31}$ Professionalism aspires to altruism, accountability, excellence, duty, service, honor, integrity, and respect for others. This is the ideal that is espoused. Learning about the reality occurs in what has been termed the "hidden" or informal curriculum. ${ }^{32}$ In fact, the socialization into medicine may result in a cynical approach of "us versus them" (see, for example, House of God by Shem). The ABIM's Project Professionalism cited a variety of challenges that threaten professionalism, such as those relating to chronic fatigue and sleep deprivation; stress and overwork; lack of confidence, self-esteem, and experience; difficult patients; chaotic, unstructured, unsupervised rotations; creative tension with other health professionals and lack of professionalism among house staff; arrogant faculty; health risks to the profession; abuse of power, and family obligations. ${ }^{28}$ Unless the medical education system deals effectively with these challenges, there may be holes that allow the graduation of individuals without the values needed to improve care and prevent error.

Medical schools and academic health centers are among the most important contributors to the culture of the practice of medicine. Situating medical schools in a university framework ensures that learning will take place in a research environment. ${ }^{33}$ This exposes students to the spirit of inquiry and its requirement for critical analysis, both of which are essential to the scientific practice of medicine. In learning to be a physician, students try to learn the ways of science as well as mastering a specific body of knowledge. However, teaching the skills required to improve care and patient safety requires qualified teachers. A "hole" in this concept is the current reward system for faculty, with its emphasis on research. In many medical schools, research activities are valued far more highly than improving one's own clinical practice or teaching. ${ }^{34}$ Academic careers depend primarily upon research publications and grants. Yet there is far more involved in the education of a medical student than ensuring that such education takes place in an environment of research and discovery. James J Duderstadt, President Emeritus of the University of Michigan, stated: "At the root of our unmet challenge in undergraduate education is the failure to distinguish between the transmission of knowledge and the development of a capacity for inquiry, discovery, and continued learning. The predicament is that the faculty is transmitting what they know and love with little awareness of what the student needs to learn" ${ }^{35}$ The issue in medical schools is the same. It has been said that "you are what you practice most". If an institution values research above all, one should not be surprised that this value is transmitted to everyone in the institution, including the students training there.

Medical students learn how to deal with error from their teachers-physicians who are themselves training in graduate medical education programs plus attending or staff physicians - as well as from the culture of the organization(s) in which they train. A study of physician trainees found that they used three major mechanisms to define and defend medical error: denial, discounting, and distancing. ${ }^{36}$ Similar observations have been made by others. ${ }^{37}{ }^{38}$ As already noted, what underlies these mechanisms is the assumption of the personal model for error; all that can be done is to be more careful next time. A marked cultural change will be necessary to create the kind of safety culture that characterizes high reliability industries. In such cultures individuals still take personal responsibility, but it doesn't end there. Safety cultures acknowledge that error will occur, value near misses, learn from error, and have respect for expertise regardless of rank. They are marked by "interpersonal responsibility; person centeredness; (co-workers) helpful and supportive of one another; friendly, open sensitive personal relations; creativity; achieving goals, strong feelings of credibility; strong feelings of interpersonal trust; and resiliency" ${ }^{39}$ Similarly, a culture of improvement supports measurement and reflection in practice, searches for the gap between what is and what could be, and rewards those who work to close that gap.

It is clear that medical students learn within several cultures, some of which may be easier to change than others. ${ }^{26}$ The underlying assumptions (such as the longstanding hierarchy of the professions) and values (such as those that inform the hidden curriculum) are deep seated. To have 
physicians finish their training prepared to improve care and patient safety, medical schools may need to favor training opportunities in healthcare organizations actively building the required environment and culture.

\section{Evaluation of learners and programs Student assessment}

Medical student assessment seeks to provide a comprehensive evaluation that ensures the graduation only of those prepared for the practice of medicine. A variety of methods are used, but few address the competencies related to improving care and patient safety. Murray et $a l^{8}$ point out that there are extensive tools for assessing clinical skills and knowledge, but fewer (and less well developed) techniques for assessing professional behavior, scholarship, and multiprofessional teamwork. There is a mismatch between what we measure and our real objectives. Furthermore, one might question the correlation between scores on "objective" (particularly multiple choice) examinations and actual performance in practice.

One major advance is the Objective Clinical Examination (OSCE). ${ }^{840}$ The OSCE is a valid and reliable method of assessing a learner's ability to apply clinical knowledge and skills in simulations of clinical encounters. Examinee performance is directly observed, albeit in a simulation. Alternatively, one might use actual patient outcomes to assess trainee performance. This also has its limitations. These outcomes depend in part on physician action, but are also affected by patient and system factors. For medical students the link between student action and patient outcomes is even more distant.

To help bridge these gaps, Coles ${ }^{7}$ suggests that we develop (rather than ignore or dismiss) the subjective judgments we make as we observe trainees in practice. This is a promising approach, but we have more to learn for such qualitative ratings to be sufficiently reliable and valid.

It is important to remember the maxim: "Tell me how I am being measured and I will tell you how I will behave". Assessment drives learning; students will prepare for what they think will be on the examination. Holes in the defences arise when there is a mismatch between what we measure and what our real objectives are. Exclusive reliance on multiple choice examinations like the National Board of Medical Examiners (NMBE) allows the graduation of students who excel on standardized tests but may lack other key skills. ${ }^{9}$ The Accrediting Council on Graduate Medical Education (ACGME), which accredits programs in graduate medical education in the US, has adopted a broader competency based approach. They now require programs training physicians in all specialties to assure competency in six core areas, including practice based learning and improvement. ${ }^{43}$ Developing valid and reliable measurements for these assessments is an area of active work. This more comprehensive approach will increase the chance that physicians will finish their training prepared to improve patient care and safety.

\section{Program accreditation}

The Liaison Committee on Medical Education (LCME) accredits programs of medical education leading to the MD degree in the US and Canada. Its process is designed to assure "that medical schools meet current national standards of structure, function, and performance, so that students receive a valid educational experience and governmental agencies have a reliable criterion for licensure" ${ }^{\prime 42}$ Programs must meet standards for accreditation "so that its graduates will be prepared to enter and complete graduate medical education, to qualify for licensure, to provide competent medical care, and to have the educational background necessary for continued learning". Similar processes operate in other countries. However, most accreditation standards are, to a large extent, still tied to the traditional model of training doctors to care for individual patients. Medical schools are not held accountable

\section{Key messages}

- Systems models of error can be applied to medical education to identify ways to increase the number of graduates prepared to reflect on and improve professional practice. This conceptual approach concentrates on seeking out and removing the error provoking properties within the system at large rather than focusing on the imperfections of individuals.

- Medical schools have mechanisms or "organizational defences" to prevent the qualification/graduation of physicians who lack the necessary competencies to practise medicine. These organizational defences include entrance requirements, the curriculum, the organizational culture of training environments, student assessment, and program evaluation.

- Each of the organizational defences against the graduation of physicians unable to improve care and patient safety has holes-that is, they are not perfect. It is these holes which must be addressed. The graduation of physicians prepared to improve care and patient safety is no accident.

for the full range of physician competencies needed. Educators must be asked to show that graduates possess the skills and attitudes needed to improve care. As with the assessment of individuals, an expanded assessment of programs requires a major effort to develop the appropriate tools and methods.

\section{CONCLUSIONS}

The graduation of physicians prepared to improve care and patient safety is no accident. It requires a unified system of education (entrance requirements, the curriculum, the culture of training environments, student assessment, and program evaluation) to ensure the development of the knowledge, attitudes, and skills needed. An analytical approach borrowed from the field of human error allows us to examine this system of education critically. In doing so, we can identify and address "holes in the defences" and increase the number of new physicians prepared to reflect on and continually improve professional practice.

\section{Authors' affiliations}

D C Aron, L A Headrick, VA National Quality Scholars Program, Louis Stokes Cleveland Department of Veterans Affairs Medical Center and Center for Healthcare Research and Policy, MetroHealth Medical Center, Case Western Reserve University School of Medicine, Cleveland, $\mathrm{OH}$, USA

\section{REFERENCES}

1 Berwick DM, Enthoven A, Bunker JP. Quality management in the NHS: the doctor's role-II. BM 1992;304:304-8.

2 Reason J. Managing the risks of organizational accidents. Brookfield: Ashgate Publishing Company, 1997.

3 Reason J. Human error: models and management. BM 2000;320:768-70.

4 Leape LL. Error in medicine. JAMA 1994;272:1851-7.

5 Borek D. Unchanging dilemmas in american medical education. Acad Med 1989;64:240-4

6 Rolfe IE, Pearson S, Powis DA, et al. Time for a review of admission to medical school? Lancet 1995:346:1329-33.

7 Coles C. Developing our intuitive knowing: an alternative approach to the assessment of doctors. In: Assessment of specialty competence in 2000. Royal College of Physicians and Surgeons of Canada, American Board of Medical Specialties Research and Education Foundation, 2000 103-14. http://www.abms.org (accessed 17 March 2002).

8 Murray E, Gruppen L, Catton P, et al. The accountability of clinical education: its definition and assessment. Med Educ 2000;34:871-9.

9 Fraser SW, Greenhalgh T. Coping with complexity: educating for capability. BM 2001;323:799-803.

10 Petersdorf RG. A matter of integrity. Acad Med 1989:64:119-23.

11 Batalden PB, Berwick D, Bisognano M, et al. Knowledge domains for health professional students seeking competency in the continual improvement and innovation of health care. Boston: Institute for Healthcare Improvement, 1998.

12 Helmreich RL. On error management: lessons from aviation. BM 2000;320:781-5. 
13 Weick K. Organizational culture as a source of high reliability. California Manage Rev 1987;2:112-27.

14 Sexton JB, Thomas EJ, Helmreich RL. Error, stress, and teamwork in medicine and aviation: cross sectional surveys. BM 2000;320:745-9.

15 Gaba DM, Howard SK, Flanagan B, et al. Assessment of clinical performance during simulated crises using both technical and behavioral ratings. Anesthesiology 1998;89:8-18.

16 Halamek LP, Kaegi DM, Gaba DM, et al. Time for a new paradigm in pediatric medical education: teaching neonatal resuscitation in a simulated delivery room environment. Pediatrics 2000;106:E45.

17 Risser DT, Rice MM, Salisbury ML. The potential for improved teamwork to reduce medical errors in the emergency department. Ann Emerg Med 1999;34:373-83.

18 Risser DT, Simon R, Rice MM. A structured teamwork system to reduce clinical errors. In: Error reduction in health care. San Francisco: Jossey-Bass, 1999: 235-78.

19 Boaden N, Leaviss J. Putting teamwork in context. Med Educ 2000;34:921-7.

20 Hall P, Weaver L. Interdisciplinary education and teamwork: a long and winding road. Med Educ 2001;35:867-75

21 O'Connor GT, Plume SK, Olmstead EM, et al. A regional intervention to improve the hospital mortality associated with coronary artery bypass graft surgery. JAMA 1996;275:841-6.

22 Pierce-Bulger $\mathbf{M}$, Nighswander T. An approach to reducing infant mortality using quality improvement principles. Qual Manage Health Care 2001;9:40-6.

23 Barr H. Working together to learn together: learning together to work together. J Interprofessional Care 2000;14:177-8.

24 Lester H, Tritter JQ. Medical error: a discussion of the medical construction of error and suggestions for reforms of medical education to decrease error. Med Educ 2001;35:855-61.

25 Davies HTO, Nutley SM, Mannion R. Organisational quality culture and quality of health care. Qual Health Care 2000;9:1 11 1-9.

26 Fox RC. The sociology of medicine: a participant observer's view. Englewood Cliffs, NJ: Prentice-Hall, 1989

27 Sinclair S. Making doctors: an institutional apprenticeship. Oxford: Oxford University Press, 1997

28 American Board of Internal Medicine (ABIM). Project professionalism. 2000. http://www.professionalism.org (accessed 17 March 2002).

29 Stern DT. Practicing what we preach? An analysis of the curriculum of values in medical education. Am J Med 1998;104:569-75.

30 Swick HM, Szenas MA, Danoff D, et al. Teaching professionalism in undergraduate medical education. JAMA 1999;282:830-2.
31 Wong RY, Hemmer PA, Szauter K. Student professionalism: a CDIM commentary. Am J Med 1999;107:537-41.

32 Hafferty FW. Beyond curriculum reform: confronting medicine's hidden curriculum. Acad Med 1998;73:403-7.

33 Ludmerer KM. Time to heal: American medical education from the turn of the century to the era of managed care. New York: Oxford University Press, 1999.

34 Aron DC, Aucott JN, Papp KK. Teaching awards and reduced departmental longevity: kiss of death or kiss goodbye? What happens to excellent clinical teachers in a research intensive medical school? http://www.med-ed-online.org/issue2.htm\#v5, 2000, 5 .

35 Duderstadt JJ. Beyond the endless frontier. Science, the endless frontier, a policy evaluation and formulation, 1996. http:// milproj.ummu.umich.edu/publications/frontier/download/frontier.pdf (accessed 14 May 2002).

36 Mizrahi T. Managing medical mistakes: ideology, insularity and accountability among internists-in-training. Soc Sci Med 1984; 19:135-46.

37 Bosk C. Forgive and remember: managing medical failure. Chicago: University of Chicago Press, 1979.

38 Rosenthal $\mathbf{M}$. The incompetent doctor: behind closed doors. Buckingham: Open University Press, 1995.

39 Roberts $\mathbf{K H}$. Cultural characteristics of reliability enhancing organizations. Managerial Issues 1993;5:165-81.

40 Dauphinee D. New ideal, new tools, new data, and old notions: assessment of specialty competence in 2000. Royal College of Physicians and Surgeons of Canada, American Board of Medical Specialties Research and Education Foundation, 2000: 67-78. http:// www.abms.org (accessed 17 March 2002).

41 ACGME. ACGME outcome project: general competencies. Version 1.3. 9-28-1999. http://www.acgme.org/outcome

42 Liaison Committee on Medical Education (LCME). Functions and structure of a medical school (accreditation and the liaison committee on medical education, standards for accreditation of medical education programs leading to the MD degree, explanatory annotations for selected accreditation standards). Part 2. 2001. www.lcme.org/functions (accessed 16 March 2002).

43 McGaghie WC, Thompson JA. America's best medical schools: a critique of the US News and World Report rankings. Acad Med 2001;76:985-92. 